\title{
Pengoptimalan estetika desain fasad dengan fungsi utama dan penunjang pada gedung serbaguna UNDIP
}

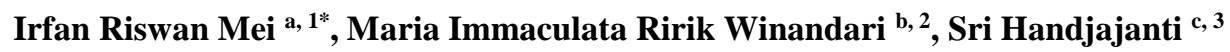 \\ a Mahasiswa Jurusan Arsitektur FTSP Universitas Trisakti, Jakarta Barat \\ b Dosen Jurusan Arsitektur FtSP Universitas Trisakti, Jakarta Barat \\ c Dosen Jurusan Arsitektur FtSP Universitas Trisakti, Jakarta Barat \\ 1 Irfanriswan052001600093@std.trisakti.ac.id*; m.ririk@trisakti.ac.id; Sri.h@trisakti.ac.id
}

\begin{tabular}{ll}
\hline Informasi artikel & ABSTRAK \\
\hline Sejarah artikel: & Sebuah kawasan sudah seharusnya memiliki karakter tersendiri yang khas. Hal \\
Diterima & yang sama berlaku juga untuk kawasan pendidikan. Salah satu cara untuk \\
Revisi & mencapai karakter khas tersebut melalui optimalisasi fasad bangunan. Gedung \\
Dipublikasikan & serbaguna UNDIP direncanakan bertaraf internasional sehingga memerlukan \\
\hline Kata kunci: & desain fasad yang optimal. Desain tersebut sudah seharusnya menyesuaikan dengan \\
Fasad & lingkungan sekitar namun terlihat modern. Perencanaan Gedung Serbaguna di \\
Ritme & kawasan tersebut memperhatikan faktor perkembangan kawasan UNDIP dengan \\
Gedung Serbaguna & mempertimbangkan penambahan fungsi, kegiatan, dan kapasitas. Paper ini \\
Kontekstual & mengeksplorasi estetika desain fasad bangunan setempat yang sesuai untuk \\
& diterapkan di Gedung serbaguna UNDIP. Metode kualitatif digunakan untuk \\
& mendapatkan desain fasad yang optimal. Variable yang dieksplorasi meliputi atap \\
& bangunan, kolom, dan ornament kaca. Hasil menunjukkan bahwa setiap sisi \\
& bangunan harus memiliki fasad sesuai bangunan sekitar. Kesesuaian tersebut \\
& meliputi atap pelana, kolom soko guru, ornament kaca dengan desain cembung.
\end{tabular}

Key word:

Facade

Rhythm

Multipurpose Building

Contextual

\begin{abstract}
Each place or area should have its own character. The same applies to education areas. The unique character can be achieved through optimization of the building's facade. UNDIP's mixed use building is planned internationally that requires an optimal façade design. The design is supposed to adapt to the surrounding environment but looks modern. The design should pays attention to the development factor of UNDIP area by considering the addition of functions, activities, and capacity. This paper explores the aesthetics of local building facade design that is suitable to be applied in UNDIP's mixed use building. Qualitative method is used to obtain optimal façade design. Variables consist of building roofs, columns, and glass ornaments. The results showed that each side of the building should have a facade according to the surrounding building. The suitability includes a saddle roof, soko guru columns, and glass ornaments with a convex design.
\end{abstract}

Copyright (C) 2018 Universitas Widya Mataram Yogyakarta. All Right Reserved

\section{Pendahuluan}

UNDIP memiliki dua gedung Serbaguna dengan taraf dan kapasitas yang berbeda. Salah satu Gedung Serbaguna tersebut dirancang bertaraf internasional dan dapat dikunjungi berbagai kalangan. Kondisi tersebut harus didukung dengan penampilan bangunan yang sesuai dengan lingkungan sekitar tetapi kelihatan modern. Penampilan tersebut dapat tercermin melalui fasad bangunan yang menyiratkan fungsi utama dan penunjang bangunan yang mampu mewadahi kegiatan penggunanya secara nyaman. Paper ini mengeksplorasi pengembangan kampus UNDIP melalui optimalisasi fasad bangunan Gedung serbaguna yang lebih baik. Perancangan Gedung Serbaguna diharapkan menjadi ikon baru kampus UNDIP yang mengedepankan tema "Estetika desain Fasad", dengan konsep Arsitektur Kontekstual. Penataan fasad bangunan diharapkan meningkatkan aspek keindahan yang dapat dinikmati oleh pengunjung di gedung tersebut. Pengunjung yang datang dapat menikmati suasana di luar bangunan dengan penghijauan alami (Prihatmaji, 2007).

Desain yang sesuai konteks membutuhkan referensi bangunan sekitar agar dapat menghargai kearifan lokal sehingga bangunan tersebut kompatibel dan selaras dengan lingkungan yang ada (Liauw, 2019). Penyesuaian dapat dilakukan dengan cara menambah, mengurangi, ataupun membongkar elemen fasad atau massa (Marlisa, 2018). Fasad bangunan dipengaruhi oleh bentuk, dimensi, komposisi, dan warna. Harani (20II) menyatakan bahwa fasad bangunan akan mempengaruhi tampilan fasade yaitu wujud, warna, dan dimensi. Menurut Ching (1995), elemen pembentuk fasad meliputi dinding, kolom, bukaan pada dinding, entrance/Drop Off, atap, 
balkon, papan tanda, warna dan finishing. Sedangkan Novis dkk (Pattileamonia, 2017) mengungkapkan bahwa fasad bangunan meliputi atap, dinding, lantai, pintu, jendela, sun shading dan sebagainya. Paper ini akan mengeksplorasi lebih lanjut mengenai atap, kolom, dan ornament bangunan di sekitar lokasi bangunan serbaguna UNDIP.

\section{Metode}

Metode penelitian ini akan memakai metode kualitatif dengan indikator pengoptimalan estetika fasad. Penelitian ini menggunakan metode pengumpulan data secara kualitatif (Creswell, 2002) yang bersifat eksploratif (Kumar, 2005). Variable yang diteliti adalah atap, kolom, dan ornament bangunan. Kasus bangunan penelitian adalah bangunan di Kawasan UNDIP yang terdiri dari Gedung serbaguna FEB, Gedung Politeknik UNDIP, dan Gedung Ekonomi UNDIP. Pengumpulan data didapat melalui studi pustaka dan google earth. Data yang sudah terkumpul dibandingkan sesuai variabelnya. Temuan penelitian didiskusikan dengan studi pustaka yang dilakukan selanjutnya.

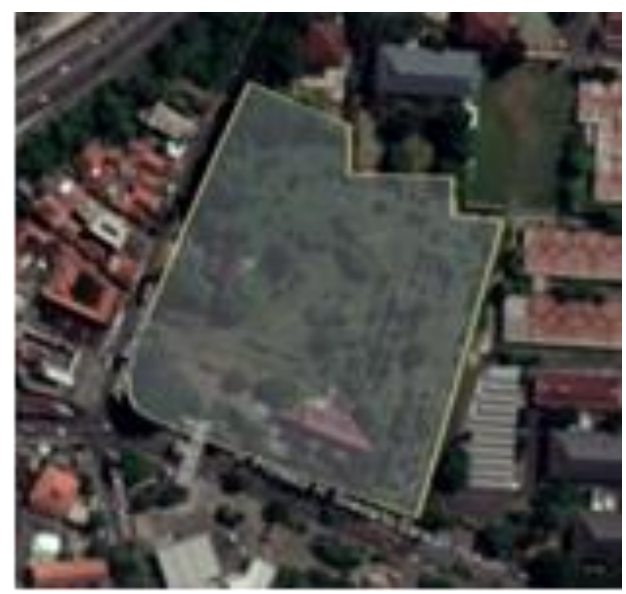

Gambar I. Tapak Bangunan

Sumber: diolah dari google earth

\section{Studi Pustaka}

Pengoptimalan estetika pada fungsi Utama dan penunjang berdasarkan fasad fungsinya yaitu fungsi Utama adalah Convention pada lobby bangunannya memiliki estetika pada kolomnya dan pada fungsi penunjang adalah Olahraga indoor dan tempat penginapan pada bangunan yaitu pada kacanya dibuatkan jenis batik semarang. Dari berdasarkan fungsi yang ada pada bangunan tersebut memiliki fungsi ruang yang tolak belakang dari jenis kegiatan yang ada. Berikut adalah jenis-jenis fungsi ruang di Gedung Serbaguna (Olahan Pribadi). Suatu Fasad Bangunan yang merupakan unsur yang tidak dapat dihilangkan dari sebuah produk desain arsitektur yang bahkan menjadi bagian penting dari sebuah karya arsitektur. Melalui fasad kita dapat menggambarkan tentang suatu fungsi-fungsi ruang yang ada dibaliknya (Ramadanta dalam Prijotomo, 2010).

Terkait dengan keselarasan dengan sekitarnya, sebuah bangunan sudah seharusnya selaras dengan konteksnya. Kontekstualisme adalah memungkinan untuk memperluaskan suatu bangunan maka keinginan untuk melibatkan bangunan baru dengan suasana sekelilingnya. dari arsitek sendiri atau persiapan bangunan dipertuakan untuk memperhatikan, menjaga dan menghargai kedaan lingkungan materi sekitarnya, mengutamakan berkelanjutan antar visibel ke konstruksi baru dengan konstruksi lama, pedoman, bahkan model sekelilingnya dengan eksistensi yang telah diakui lebih dahulu (Brolin, 1980). Arsitektur bangunan seperti tempat tinggal rumah joglo terorganisasi dari konstruksi luar yang tidak terlalu kelihatan dan konstruksi dalam yang tidak kelihatan, dan keduanya bersambungan antar dengan yang lain. Hubungan dari konstruksi rumah konservatif Jawa yang mengilustrasikan kedalaman nilai (Subiyantoro, 20I I).

\section{A. Bentuk Atap \\ I. Atap Pelana}

Bentuk atap pelana sering disebut sebagai bentukan yang sederhana. Bentuk atap pelana yang tersusun atas dua sisi bidang atap yang bertemu pada garis atau disebut bubungan. Sudut kemiringan atap pelana pada dasarnya $30-45^{\circ}$ (Murti 2020). 


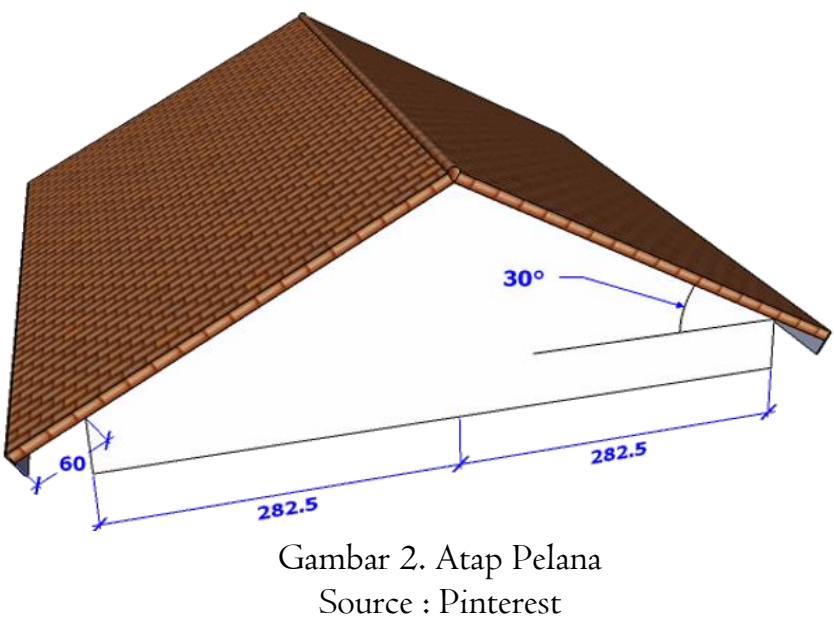

2. Gevel

Gevel merupakan dinding penerus yang digunakan sebagai pendukung penutup atap. Gevel biasanya hanya digunakan sebagai penutup fasade bangunan. Bentuk gevel dasarnya geometris, dengan betuk kotak, segitiga, ataupun digabung dua-duanya (Murti 2020).

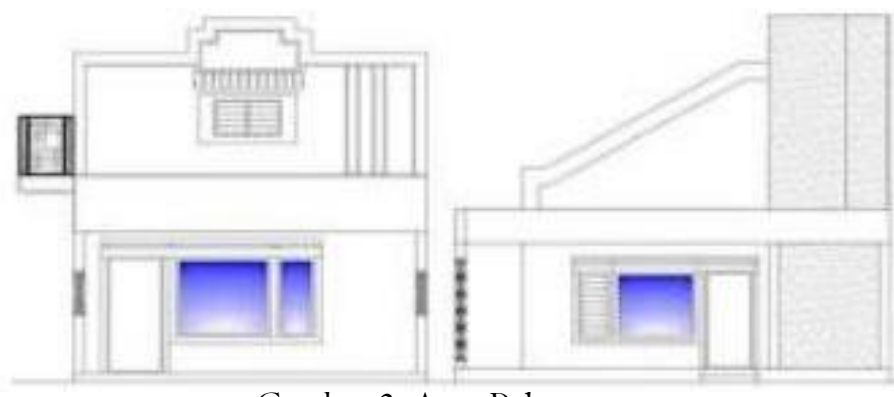

Gambar 3. Atap Pelana

Source : Murti 2020

\section{Atap Perisai}

Bentuk atap perisai atau sering disebut atap limas tersusun atas 4 bidang atap, dengan dua bidang atap yang bertemua pada satu garis bubungan jurai dan dua bidang atap bertemu pada garis bubungan atas pada fasade bangunan, atap perisai dapat terlihat dengan bentuk trapezium dan bentuk segitiga. Pada bentuk atap perisai cenderung tinggi dengan sudut kemiringan $>30^{\circ}$ dengan bahan materialnya gabungan antara kayu dan baja ringan(Murti 2020).

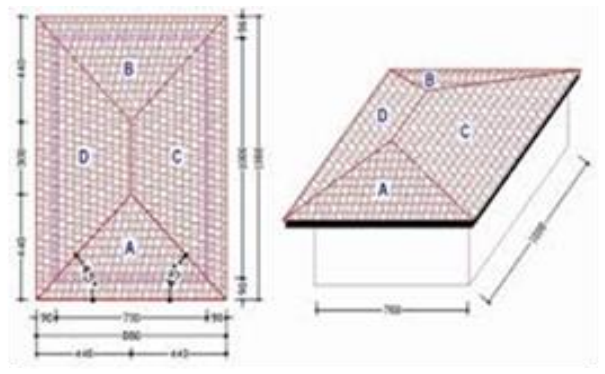

Gambar 4. Atap Perisai

Source : www.wordpress.rumah.joglo.com

\section{B. Bentuk kolom}

Setiap rumah joglo merupakan bentuk yang paling dominan bagi arsitektur jawa, bahkan jika mendengar kata arsitektur jawa ada bentuk joglo yang seolah-olah menjadi ciri khas. Bentuk dan penforma pendopo joglo dipengaruhi oleh atap, umpak, dan jumlah kolom. Terdapat 3 jenis soko guru dari beberapa riset yang dilakukan 
yaitu soko guru, soko penitih, dan soko pengarak (Ronald I998). Pada kolom sopo guru memiliki 4 tiang yang berhadapan dengan langsung ke halaman parkir pada umumnya dan memakai bahan kayu jati lalu pondasinya berupa umpak dari beton. Pemakaian kolom sopo guru memiliki struktur tradisional dengan dengan bentuk kotak memanjangn dan berwarna coklat tua. Bentukan modern yang dibuat adalah lingkaran tetapi dari sisi warna tetap memakai warna coklat tua. Bentuk lingkaran adalah bentuk ideal yang akan digunakan gedung bentang lebar dan mempunyai kekuatan yang kokoh(Moniaga and Gunawan 2019).

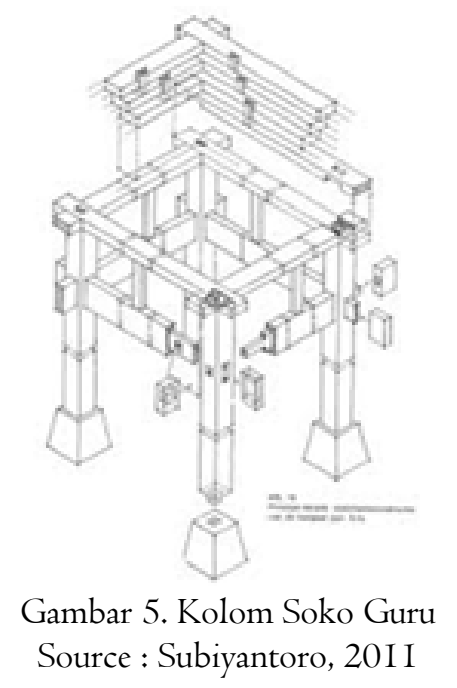

C. Bentuk ornament

Ragam hias ornamen jawa banyak bentuknya dengan lebih mementingkan estetika dan tanpa mempengaruhi fungsi, namun kepercayaan jaman dulu memiliki fungsi filosofis. Untuk ragam hias pada bangunan jawa memiliki 5 bentuk ragam hias berdasarkan motif hias yaitu Flora, Fauna, Alam, Agama, dan Anyam-Anyaman (Iswanto 2008).

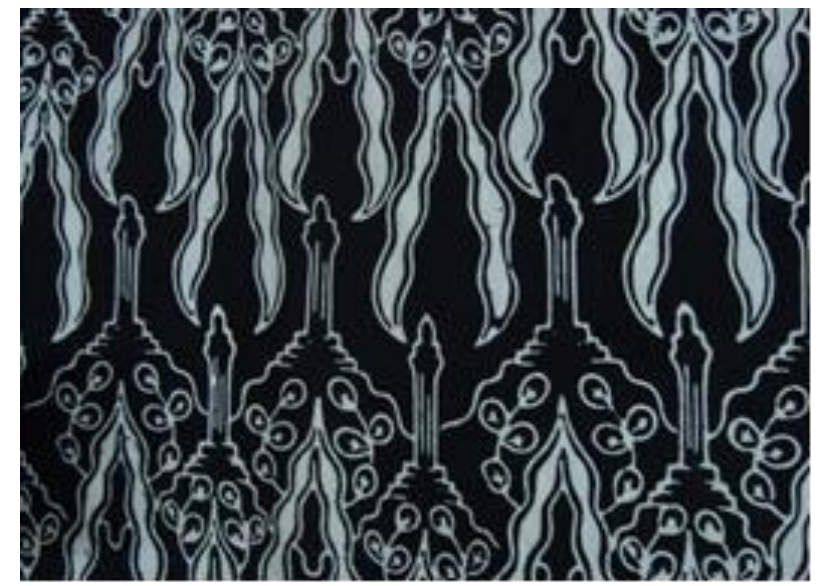

Gambar 6. Batik Semarang

Source : https://infobatik.id/582-2/

\section{Hasil dan pembahasan}

Ketiga bangunan merupakan bangunan di dalam kampus UNDIP. Pembahasan meliputi atap, kolom, dan ornament.

\section{A. Atap bangunan UNDIP}

Dari berbagai jenis Atap yang telah dibandingkan yaitu atap pelana yang sesuai dengan bentuk bangunan yang telah kedesain. Atap yang diterapkan yaitu bentukan dari atap perisai tapi berupa atap modern yang memakai struktur baja ringan. Atap perisai yaitu terbentuk dari dua bidang yaitu berupa Trapesium dan dua lagi 
memiliki bidang segitiga yang semuanya akan bertemu di puncak atau bubungan dalam penggunaan strukturnya memakai struktur space frame. Penggunaan atap pelana mengikuti pada bangunan utama di UNDIP yaitu gedung Ekonominya. Lalu di bagian tengah atapnya akan ada Void garden yang akan mendukung estetika pada bangunan meskipun dari atap.

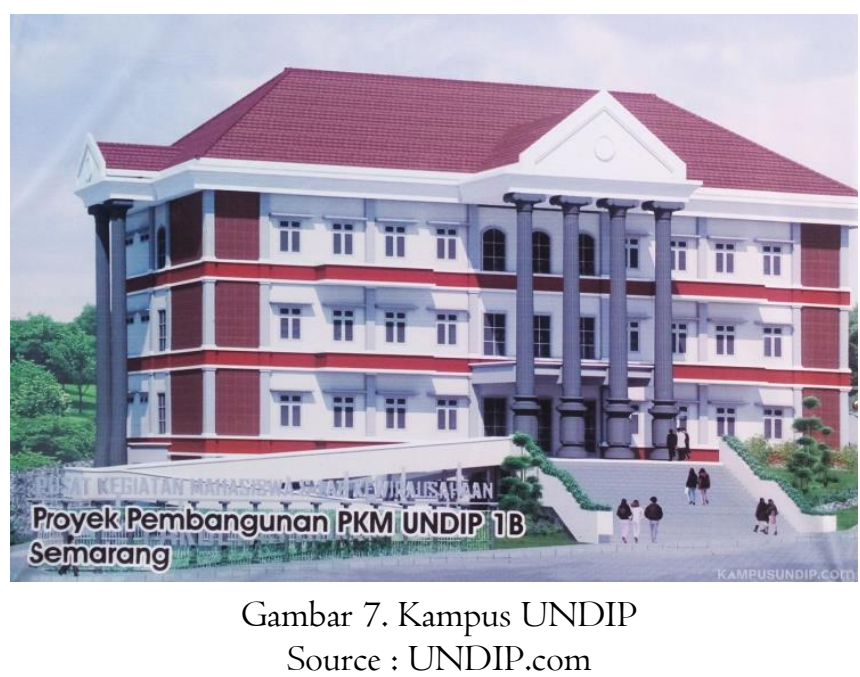

\section{B. Kolom bangunan UNDIP}

Kolom gedung ekonomi berbentuk bulat sedangkan kedua gedung lain berbentuk kotak. Seperti yang telah diungkapkan Pada konstruksi penggunaan kolom akan memberi kesan estetika dikarenakan akan ditambahkan pondasi umpak. Hal yg berbeda yaitu dari bahan materialnya menggunakan beton biasanya penggunaan pondasi umpak memakai kayu jati muda. Kolom dan strukturnya yang begitu kokoh dan sangat kuat bagi kondisi alam yaitu berupa gempa. Kolom yang akan ditentukan yaitu berbentuk bulat dan dilapisi cincin yang akan memberikan efek pencahayaan yang natural pada malam hari.

\section{Ornamen bangunan UNDIP}

Ornament gedung ekonomi memiliki ragam hias yaitu Flora dengan jenisnya Lung-Lungan berarti tumbuhan yang melata dan masih muda. Gedung serbaguna FEB memiliki lambang UNDIP di bagian fasad bagian depan bangunan sedangkan Gedung politeknik UNDIP tidak memiliki ornament. Seperti yang telah diungkapkan pada table tersebut.

Tabel I memperlihatkan perbandingan ketiga kasus bangunan yaitu Gedung ekonomi UNDIP, Gedung Serbaguna (FEB), dan Politeknik UNDIP.

Tabel I. Perbandingan

\begin{tabular}{|c|c|c|c|c|}
\hline & $\begin{array}{l}\text { Gedung } \\
\text { ekonomi } \\
\text { Undip }\end{array}$ & $\begin{array}{l}\text { Gedung } \\
\text { Serbaguna } \\
\text { (FEB) }\end{array}$ & $\begin{array}{l}\text { Politeknik } \\
\text { UNDIP }\end{array}$ & Temuan \\
\hline Bentuk Atap & Atap Pelana & Atap Pelana & Atap Pelana & Atap pelana \\
\hline Bentuk Kolom & Bulat & Kotak & Kotak & Kotak dan bulat \\
\hline $\begin{array}{l}\text { Ornamen } \\
\text { Bangunan }\end{array}$ & $\begin{array}{l}\text { Motif Flora } \\
\text { Lung-Lungan } \\
\text { di atap }\end{array}$ & $\begin{array}{l}\text { Lambang } \\
\text { UNDIP Depan } \\
\text { fasad }\end{array}$ & Tanpa ornamen & $\begin{array}{ll}\text { Ornamen } & \text { Flora } \\
\text { dan Fauna } & \end{array}$ \\
\hline
\end{tabular}

\section{Simpulan}

UNDIP memiliki dua gedung serbaguna yang memiliki taraf dan kapasitas yang berbeda-beda. Meskipun memiliki gedung serbaguna yang berbeda tapi hal kualitas dan kuantitas yang dimiliki bangunan berbeda dari yang lain. Dalam pemilihan fungsi juga berpengaruh terhadap beberapa point-point estetika yang berlaku pada penerapan Kontekstual terhadap bangunan sekitar yang dijadikian pedoman atau ilustrasi desain yang akan diterapkan. Estetika kontekstual pada bangunan memiliki 3 titik yaitu fasad pada atap, kolom dan ornament pada 
kaca. Bangunan yang di desain semaksimal mungkin akan memberi kesan tersendiri dan karakter bangunannya bagi. Estetika pada bangunan mengikuti dengan desain sekitar yaitu pada gedung Ekonomi UNDIP.
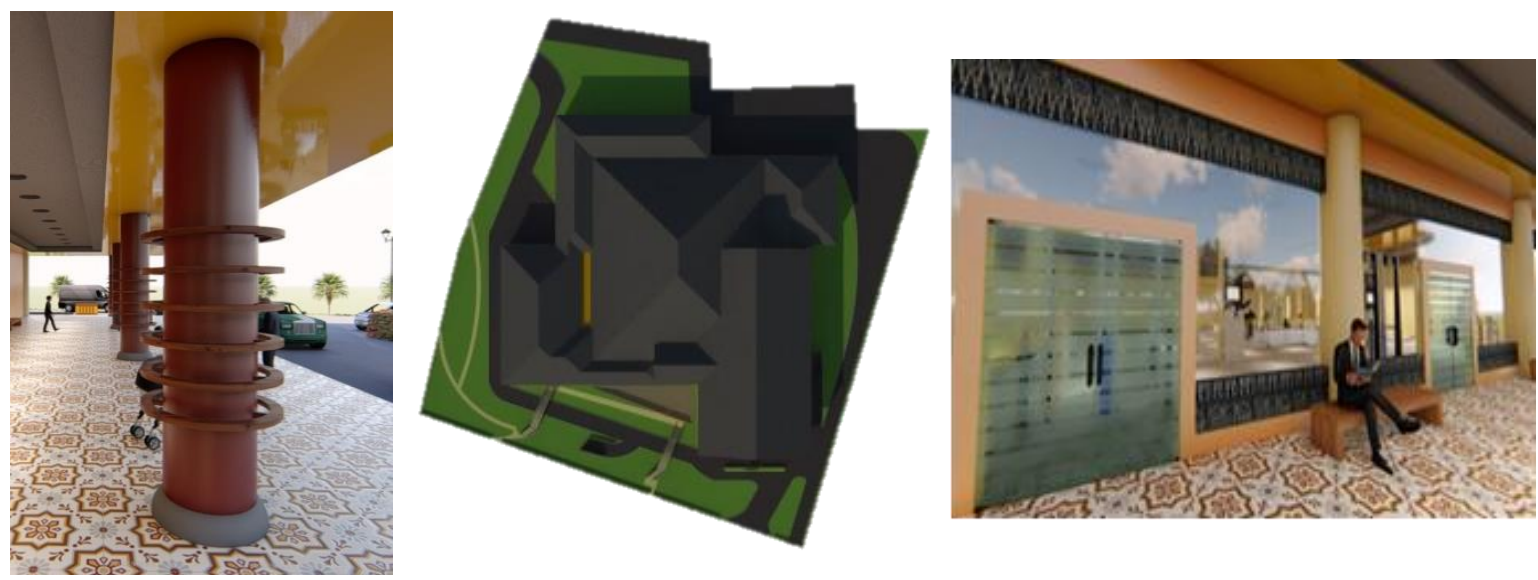

Gambar 8. Desain Jadi

\section{Referensi}

- Alexander, Christopher. The timeless way of building. Vol. I. New York: Oxford University Press, 1979

- Brolin C. Brent; 1980; Architecture in Context, Van Nostrand Reinhold Company, New York.

- Ching, D. K. 1995 Visual Dictionary of Architecture. Wiley, John \& Sons, Incorporated

- Djelantik, Anak Agung Made, Taufik Rahzen, and Ni Nyoman Manik Suryani. Estetika: sebuah pengantar. Masyarakat Seni Pertunjukan Indonesia, 1999.

- Eny Iryanti, Veronika. 2016. "Kenikmatan Estetis Dalam Seni Suatu Tinjauan Filosofis." Imaji I4(2):139_ 45.

- Hardy, I. Gusti Ngurah Wiras. 2020. “Konsep-Konsep Lokal Yang Melatarbelakangi Sistem Penghawaan Dan Pencahayaan Rumah Tradisional Di Dusun Pucung, Jawa Tengah.” Langkau Betang: Jurnal Arsitektur 7(I):I.

- History of Batik, https://infobatik.id/582-2/ (di akses pada tanggal 9 mei 2020)

- Huang, Ming-Zhu, and W. Y. Ching. "A minimal basis semi-ab initio approach to the band structures of semiconductors." Journal of Physics and Chemistry of Solids 46.8 (I985): 977-995

- Iswanto, Danoe. 2008. “Aplikasi Ragam Hias Jawa Tradisonal Pada Rumah Tinggal Baru.” Jurnal Ilmiah Perancangan Kota Dan Permukiman 7(2):90-97.

- Lawson, Fred.I98I Conference, Convention and Exhibition Facilities, The Architecture Press, London

- Liauw, Franky. 2019. "Reference for Contextual Design." IOP Conference Series: Materials Science and Engineering 508(I)

- Ronald, A., Santosa, M., and Saragih, S., (I988). "JOGLO BUILDING a study of construction, proportion \&structure of royal house in Yogyakarta". Departement of architecture engineering faculty - UGM

- Neufert, Ernst, (I99I), Data Arsitek Jilid 2 Edisi 33. Erlangga. Ciracas, Jakarta

- Moniaga, Christian, and Alvina Gunawan. 2019. "Rumah Joglo Sebagai Identitas Visual Konsep Bangunan Kuliner Kontemporer.” Desain Komunikasi Visual Dan Media Barusain Komunikasi Visual Dan Media Baru I(2):I3-23.

- Murti, Siti. dan heryanto. 2020. "Jurnal Ilmiah Wahana Pendidikan.” Jurnal Ilmiah Wahana Pendidikan Https://Jurnal.Unibrah.Ac.Id/Index.Php/JIWP 6(3):295-307

- Prihatmaji, Yulianto P. 2007. "PERILAKU RUMAH TRADISIONAL JAWA \&quot;JOGLO\&quot; TERHADAP GEMPA.” DIMENSI (Journal of Architecture and Built Environment) 35(I):I-I2. 
Irfan Riswan Mei, dkk | Pengoptimalan estetika desain fasad dengan fungsi utama dan penunjang pada gedung serbaguna UNDIP

- Rahmi, Marlisa, Zulhadi Sahputra, Allis Nurdini, Jurusan Arsitektur, Fakultas Teknik, Universitas Syiah Kuala, and Banda Aceh. n.d. "Kajian Tipologi Terhadap Perubahan Elemen Fasad Ruko Ditinjau Dari Jenis Fungsi Layanan Kasus Studi : Ruko Paskal Hyper Square Bandung.” 7(10):195-202

- Subiyantoro, Slamet. 20I I. "Rumah Tradisional Joglo Dalam Estetika Tradisi Jawa." Bahasa Dan Seni 39(I):68-78. 